\title{
Patient Satisfaction and Quality of Life Before and After Treatment of Pancreatic and Periampullary Cancer: A Prospective Multicenter Study
}

Tara M. Mackay, MD'; Lennart B. van Rijssen, $\mathrm{MD}^{1}$; Jurr O. Andriessen, $\mathrm{BSc}^{1}$; Mustafa Suker, $\mathrm{MD}^{2}$; Geert-Jan Creemers, MD, $\mathrm{PhD}^{3}$; Ferry A. Eskens, MD, $\mathrm{PhD}^{4}$; Ignace H. de Hingh, MD, $\mathrm{PhD}^{5}$; Lonneke V. van de Poll-Franse, PhD 6 ,7,8; Mirjam A.G. Sprangers, $\mathrm{PhD}^{9}$; Olivier R. Busch, MD, PhD ${ }^{1}$; Johanna W. Wilmink, MD, PhD ${ }^{10}$; Casper H. van Eijck, MD, PhD²; Marc G. Besselink, MD, PhD'; and Hanneke W. van Laarhoven, MD, PhD ${ }^{10}$; on behalf of the Dutch Pancreatic Cancer Group

\section{ABSTRACT}

Background: This study sought to assess patient satisfaction and quality of life ( $\mathrm{Q} \circ \mathrm{L})$ before and after treatment of pancreatic and periampullary cancer. Methods: We conducted a prospective multicenter study of patients treated for pancreatic and periampullary cancer. General patient satisfaction was measured using the EORTC satisfaction with care questionnaire (IN-PATSAT32) at baseline and 3 months after treatment initiation, with a 10-point change on the Likert scale considered clinically meaningful. QoL was measured using the EORTC Core Quality of Life Questionnaire (QLQ-C30). The influence of treatment (curative and palliative) on patient satisfaction and QoL was determined. Results: Of 100 patients, 71 completed follow-up questionnaires. General satisfaction with care decreased from 74.3 before treatment to 61.9 after treatment $(P<.001)$, whereas global CoL increased from 68.4 to $71.4(P=.39)$. Clinically meaningful reductions were also observed for the reported interpersonal skills of doctors (from 73.4 to 63.3) and exchange of information within the care team (from 63.5 to 52.5). Satisfaction scores were lower for patients treated with curative intent than for those treated with palliative intent regarding interpersonal skills of doctors $(P=.01)$, information provision by doctors $(P=.004)$, information provision by nurses $(P=.02)$, availability of nurses $(P=.004)$, exchange of information within the care team $(P=.01)$, and hospital access $(P=.02)$. In multivariable analysis, clinicopathologic or QoL factors were not independently associated with general patient satisfaction. Conclusions: Satisfaction with care, but not QoL, decreased after pancreatic cancer treatment. Improvements in communication and interpersonal skills are needed to maintain patient satisfaction after treatment.

J Natl Compr Canc Netw 2020;18(6):704-711 doi: $10.6004 /$ jnccn.2020.7528

\footnotetext{
${ }^{1}$ Department of Surgery, Cancer Center Amsterdam, Amsterdam UMC, University of Amsterdam, Amsterdam; ${ }^{2}$ Department of Surgery, Erasmus Medical Center, Rotterdam; ${ }^{3}$ Department of Medical Oncology, Catharina Hospital, Eindhoven; ${ }^{4}$ Department of Medical Oncology, Erasmus Medical Center, Rotterdam; ${ }^{5}$ Department of Surgery, Catharina Hospital, Eindhoven; ${ }^{6}$ Department of Medical Psychology, Tilburg University, Tilburg; ${ }^{7}$ Department of Psychosocial Oncology and Epidemiology, Netherlands Cancer Institute, Amsterdam; ${ }^{8}$ Netherlands Comprehensive Cancer Organization, Utrecht; and ${ }^{9}$ Department of Psychology, and ${ }^{10}$ Department of Medical Oncology, Cancer Center Amsterdam, Amsterdam UMC, University of Amsterdam, Amsterdam, the Netherlands.
}

\section{Background}

In line with developments toward patient-centered care, patient satisfaction is increasingly being recognized as an important outcome measure ${ }^{1}$ and indicator of hospital quality. ${ }^{2}$ Measuring patient satisfaction next to quality of life (QoL) may be useful to identify potential areas of improvement. ${ }^{3-5}$ Higher patient satisfaction has been associated with better treatment compliance, a better doctor-patient relationship, and even improved survival in patients with cancer. ${ }^{6-9}$

Patient satisfaction is especially relevant in cancer care because of the limited survival, which is characterized by intense and complex treatments associated with frequent hospital visits, adverse events, and (re)interventions. This is particularly true in patients with pancreatic and periampullary cancer, which are among the deadliest cancers. ${ }^{10-12}$ Up to $80 \%$ of patients with pancreatic cancer are diagnosed with nonoperable, locally advanced, or metastatic disease. Although new systemic therapies have shown significant survival benefits in recent years, they increase the risk of severe toxicity. ${ }^{10,13,14}$ A minority of patients are eligible for surgical resection, which provides a 5-year survival rate of $25 \%$ if combined with adjuvant chemotherapy. However, again, both pancreatic surgery and adjuvant treatment are accompanied by high complication rates. ${ }^{10,15}$ Because of the complex treatments and limited survival, patient satisfaction and QoL are particularly important in the care of patients with pancreatic and periampullary cancer. ${ }^{16}$

QoL may be influenced by characteristics of the healthcare organization, the patient, and the disease itself. ${ }^{17,18}$ The exact relationship between patient satisfaction

See JNCCN.org for supplemental online content. 
and QoL is unclear. Therefore, this study aimed to assess patient satisfaction with pancreatic and periampullary cancer treatment and its relationship with QoL. In addition, we aimed to identify potential clinicopathologic factors that have a relationship with patient satisfaction. We hypothesized that patients treated in the palliative setting would display lower satisfaction with care than those treated in the curative setting. Our findings will inform healthcare providers about patients' needs and expectations during the treatment of pancreatic and periampullary cancer and provide options to improve patient satisfaction.

\section{Methods}

\section{Patients}

A prospective cohort of 100 patients with newly diagnosed pancreatic or periampullary cancer in June 2015 through April 2016 was enrolled from 3 Dutch pancreatic centers: Amsterdam UMC, Academic Medical Center (Amsterdam); Catharina Hospital (Eindhoven); and Erasmus Medical Center (Rotterdam). This study was part of a pilot study of the Dutch Pancreatic Cancer Project (www.pacap.nl) performed by the Dutch Pancreatic Cancer Group (www.dpcg.nl) to investigate patient-reported outcomes. ${ }^{19}$ Patients received either curative or palliative treatment as defined later. Patients returning the baseline questionnaire after treatment initiation were excluded, as were those who were not fluent in Dutch or could not complete the questionnaires for mental reasons. For measurement of the QoL and satisfaction with care questionnaires, a waiver was obtained for the informed consent procedure from the Amsterdam UMC, Academic Medical Center Institutional Review Board.

Patients were approached for participation within 1 week after diagnosis. Patients could choose to complete an online or paper questionnaire. ${ }^{20}$ Automated reminders were sent in case of nonresponse. Patients who did not return the follow-up questionnaire after a reminder were contacted by telephone and asked to complete the questionnaire over the telephone (L.B. van Rijssen). Deceased patients were excluded from the calculation of questionnaire return rates.

\section{Questionnaires}

Patients completed the Dutch versions of the EORTC cancer in-patient satisfaction with care questionnaire (IN-PATSAT32) and the EORTC Core Quality of Life Questionnaire (QLQ-C30) before treatment and 3 months after inclusion. The IN-PATSAT32 measures patients' selfperceived satisfaction with care via 32 items that are categorized into 11 multi-item and 3 single-item domains. ${ }^{21}$ These include measures of doctor and nurse technical skills, interpersonal skills, information provision, and availability; satisfaction with other hospital staff members' kindness and helpfulness, interpersonal skills, and information provision; exchange of information within the care team; waiting time; hospital access; hospital comfort; and overall satisfaction with care. The scoring procedure for the IN-PATSAT32 module generates a score of 0 to 100 for each (single-item and multiitem) domain. A higher score reflects a higher level of satisfaction.

The QLQ-C30 measures QoL in patients with cancer via 30 items that are categorized into 9 multi-item domains and 6 single-item domains. ${ }^{22}$ These include 5 functioning scales (physical, role, cognitive, emotional, and social), 3 symptom scales (fatigue, pain, and nausea and vomiting), a global QoL scale, and 6 symptoms commonly reported by patients with cancer (dyspnea, insomnia, appetite loss, constipation, diarrhea, and financial difficulties). The scoring procedure for the QLQ-C30 also generates a score of 0 to 100 for each (single-item and multi-item) scale. A higher score for a functioning domain and global QoL represents a better level of functioning. A higher score for a single-item or multi-item symptom domain suggests a higher level of symptoms.

\section{Clinical Data and Definitions}

Sociodemographic and clinical data were retrieved from the relevant medical charts at the participating centers. Extracted baseline characteristics were age, sex, education level, ECOG performance status, histopathologic diagnosis (occasionally omitted if patients desired no additional treatment or no pathologic confirmation was available), treatment type, and starting date of treatment. Curative treatment was defined as a pancreatic with curative intent. For patients in good postoperative clinical condition, adjuvant chemotherapy was offered. Palliative treatment was defined as any palliative systemic treatment of metastatic or locally advanced pancreatic or periampullary cancer. The start of treatment was defined as upfront surgery or chemotherapy initiation.

\section{Statistical Analysis}

Data were analyzed using SPSS Statistics, version 21 (IBM Corp). Normally distributed continuous data were presented as means with standard deviations, and nonnormally distributed continuous data were presented as medians with interquartile ranges. Categorical data were presented as frequencies with percentages. IN-PATSAT32 and QLQ-C30 scores were expressed as means with standard deviations and compared with the corresponding 
baseline score using paired $t$ tests and Wilcoxon tests as appropriate. Cronbach's $\alpha$ was calculated when possible to evaluate each multi-item scale's internal consistency. Following Osoba et al, ${ }^{23}$ a change of 10 points on IN-PATSAT32 score was considered clinically meaningful. Only clinically meaningful changes in IN-PATSAT32 scores were reported. A change of 10 points in QLQ-C30 scores was considered clinically meaningful, wherein a change of 5 to 9 indicated a small difference, 10 to 20 a moderate difference, and $>20$ a large difference. ${ }^{23}$ Mean differences in IN-PATSAT32 scores were compared using unpaired $t$ tests between patients treated with curative intent and those treated with palliative intent. Sensitivity analysis was performed, excluding patients with diagnoses other than pancreatic or periampullary adenocarcinoma $(n=8)$. Standard multivariable linear regression was used to identify predictors of general satisfaction with care scores after treatment. Included in the regression analysis were clinical variables, the QLQ-C30 score for global QoL, and all 5 functioning scales. QLQ-C30 symptom scales were omitted because it was believed that for the purpose of this study, these were sufficiently reflected in the physical functioning scale. Variables with a $P$ value $<.20$ in univariable analysis were entered into the multivariable model. Outcomes of the multivariable analysis were reported as $\beta$ regression coefficients with the corresponding 95\% confidence intervals. A $P$ value $<.05$ was considered statistically significant.

\section{Results}

\section{Patients and Characteristics}

Mean age of the cohort was 66 years and $61 \%$ were men. One patient died of severe cholangitis shortly after inclusion and did not complete any questionnaires. Median time between treatment initiation and the follow-up questionnaire was 13 weeks. Six patients $(6 \%)$ completed the baseline questionnaire after treatment initiation (range, 2-21 days after start of treatment) and were excluded. Therefore, 93 of 99 patients (94\%) completed the baseline questionnaire and were available for analysis, and of these, 71 (76\%) completed the followup questionnaire. During follow-up, 8 patients died, 8 declined further participation, and 6 were lost to follow-up. A flowchart depicting patient accrual is shown in Figure 1.

Of the 71 patients who completed both questionnaires, $40(56 \%)$ received treatment with curative intent and $31(44 \%)$ received treatment with palliative intent. Among those treated with curative intent, none received neoadjuvant chemotherapy, 13 (33\%) received surgery alone, and $27(68 \%)$ received surgery with adjuvant chemotherapy during this study. Baseline patient characteristics are summarized in Table 1 .

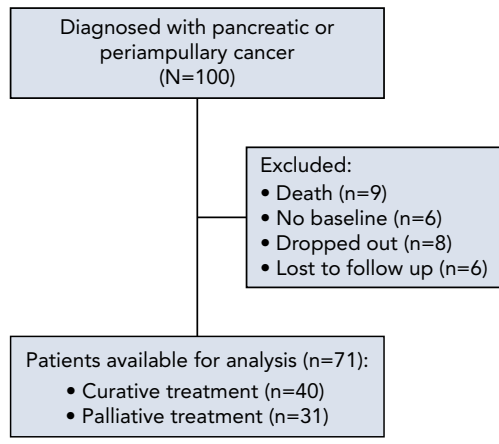

Figure 1. Patient selection and questionnaire return rates.

Impact of Treatment on Patient Satisfaction and QoL Satisfaction with care before and after treatment is shown in Table 2. Cronbach's $\alpha$ coefficients were $\geq 0.70$ for all IN-PATSAT32 domains, indicating good internal consistency. After treatment, reductions of IN-PATSAT32 scores were observed for 3 of 14 domains: general satisfaction with care (from 74.3 to 61.9), satisfaction with the interpersonal skills of doctors (from 73.4 to 63.3), and exchange of information within the care team (from 63.5 to 52.5).

QoL before and after treatment is shown in Table 3. Global QoL increased from 68.4 to 71.4 (not clinically meaningful). Small changes in QLQ-C30 scores ( $<10$ points) were observed for physical functioning, cognitive functioning, social functioning, and fatigue. Moderate changes in QLQ-C30 scores were observed for role functioning and insomnia, and both were clinically meaningful ( $\geq 10$ points). Sensitivity analyses excluding patients with diagnoses other than pancreatic or periampullary adenocarcinoma showed satisfaction with care and QoL before and after treatment remained similar to primary results (supplemental eTables 1 and 2, available with this article at JNCCN.org).

\section{Treatment Type and Patient Satisfaction}

Figure $2 \mathrm{~A}-\mathrm{C}$ show the mean differences in satisfaction scores before and after treatment for patients treated with curative and palliative intent separately. A clinically meaningful reduction (ie, a change $\geq 10$ points, depicted by the dotted lines in Figure 2) in patient satisfaction among patients treated with curative intent was observed for the domains of general satisfaction with care, technical skill of doctors, interpersonal skill of doctors, availability of doctors, availability of nurses, and exchange of information within the care team. A clinically meaningful reduction in patient satisfaction among patients treated with palliative intent was observed for general satisfaction with care.

The mean difference in general satisfaction with care among patients treated with curative intent was -12.5 compared with -12.1 among patients treated with palliative 


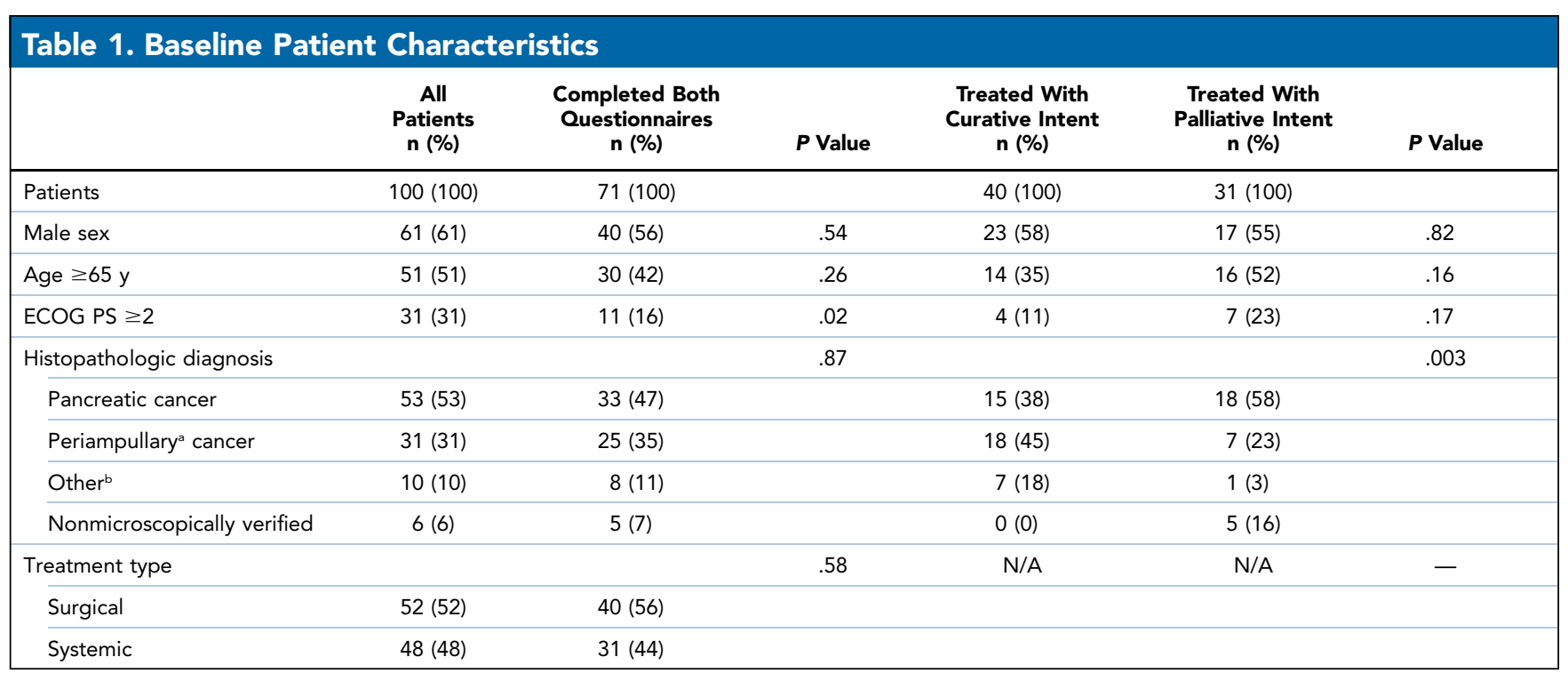

Abbreviations: N/A, not applicable; PS, performance status.

aRefers to duodenum, distal bile duct, and papilla of Vater.

bIncludes intraductal papillary mucinous neoplasm $(n=3)$, pancreatic neuroendocrine tumor $(n=1)$, serous cystadenoma $(n=1)$, solid pseudopapillary neoplasm $(n=1)$, and not specified $(n=1)$.

intent. For 6 domains, satisfaction scores were significantly lower among patients treated with curative versus palliative intent. This included the interpersonal skills of doctors (mean [SD], $-14.0[ \pm 15.7]$ vs $-4.7[ \pm 20.0] ; P=.013$ ), information provision by doctors $(-8.9[ \pm 16.3]$ vs $0.9[ \pm 12.5]$; $P=.004)$, information provision by nurses $(-8.4[ \pm 11.4]$ vs $-2.7[ \pm 16.0] ; P=.02)$, availability of nurses $(-12.8$ [ \pm 12.6$]$ vs $-2.9[ \pm 16.0] ; P=.004)$, exchange of information
$(-14.5[ \pm 19.0]$ vs $-6.1[ \pm 15.4] ; P=.01)$, and hospital access $(-8.1[ \pm 16.6]$ vs $-1.3[ \pm 14.1] ; P=.02)$.

\section{Associations Between QoL and Patient Satisfaction} In univariable analysis, only better cognitive functioning (measured by QLQ-C30) was associated with increased general satisfaction with care $(\beta=0.2 ; 95 \% \mathrm{CI}, 0.02-0.3$; $P=.03)$. Yet, after multivariable analysis, no factors were

Table 2. IN-PATSAT32 Scores Before and After Treatment

\begin{tabular}{|c|c|c|c|c|c|c|}
\hline & \multicolumn{2}{|c|}{ Before Treatment } & \multicolumn{2}{|c|}{ After Treatment } & \multirow[b]{2}{*}{$P$ Value } & \multirow{2}{*}{$\begin{array}{c}\text { Clinically } \\
\text { Meaningfu }\end{array}$} \\
\hline & Mean & SD & Mean & SD & & \\
\hline General satisfaction with care & 74.3 & 10.7 & 61.9 & 12.4 & $<.001$ & Yes \\
\hline Doctor interpersonal skills & 73.4 & 13.2 & 63.3 & 14.1 & $<.001$ & Yes \\
\hline Doctor technical skills & 75.6 & 11.5 & 66.0 & 14.6 & $<.001$ & - \\
\hline Doctor information provision & 73.2 & 12.7 & 68.4 & 14.0 & .01 & - \\
\hline Doctor availability & 68.8 & 13.3 & 60.7 & 14.0 & $<.001$ & - \\
\hline Nurse interpersonal skills & 72.7 & 10.5 & 67.0 & 12.6 & $<.001$ & - \\
\hline Nurse technical skills & 73.3 & 10.8 & 68.8 & 11.8 & .01 & - \\
\hline Nurse information provision & 68.9 & 9.3 & 62.9 & 11.5 & $<.001$ & - \\
\hline Nurse availability & 67.6 & 9.6 & 58.9 & 12.3 & $<.001$ & - \\
\hline Other hospital staff & 68.8 & 9.7 & 59.6 & 8.3 & $<.001$ & - \\
\hline Waiting time & 61.6 & 12.4 & 57.8 & 12.6 & .08 & - \\
\hline Hospital access & 61.5 & 12.0 & 56.2 & 12.7 & .01 & - \\
\hline Exchange of information & 63.5 & 14.1 & 52.5 & 11.9 & $<.001$ & Yes \\
\hline Hospital comfort & 62.7 & 12.1 & 59.1 & 11.3 & .07 & - \\
\hline
\end{tabular}

Abbreviation: IN-PATSAT32, EORTC cancer in-patient satisfaction with care questionnaire. 
Table 3. QLO-C30 Scores Before and After Treatment

\begin{tabular}{|c|c|c|c|c|c|c|}
\hline & \multicolumn{2}{|c|}{ Baseline } & \multicolumn{2}{|c|}{ Posttreatment } & $P$ Value & $\begin{array}{c}\text { Clinically } \\
\text { Meaningfu }\end{array}$ \\
\hline Global quality of life & 68.4 & 17.2 & 71.4 & 20.1 & .39 & - \\
\hline Physical functioning & 82.6 & 17.0 & 77.6 & 18.5 & .06 & - \\
\hline Role functioning & 82.8 & 21.5 & 67.2 & 27.2 & $<.001$ & Yes \\
\hline Emotional functioning & 78.8 & 19.2 & 75.0 & 22.6 & .22 & - \\
\hline Social functioning & 80.6 & 22.2 & 74.6 & 23.7 & .12 & - \\
\hline Fatigue & 34.9 & 22.3 & 42.2 & 25.4 & .08 & - \\
\hline Nausea and vomiting & 19.4 & 27.1 & 20.8 & 23.2 & .75 & - \\
\hline Pain & 27.4 & 23.7 & 26.9 & 27.2 & .90 & - \\
\hline Dyspnea & 13.8 & 22.7 & 16.9 & 24.4 & .40 & - \\
\hline Diarrhea & 18.7 & 26.9 & 20.7 & 26.0 & .63 & - \\
\hline Financial difficulties & 68.4 & 17.2 & 71.4 & 20.1 & .11 & - \\
\hline
\end{tabular}

Abbreviation: QLQ-C30, EORTC Core Quality of Life Questionnaire.

found to be independently associated with general patient satisfaction (Table 4).

\section{Discussion}

This prospective multicenter study found that patient satisfaction decreased after treatment of pancreatic or periampullary cancer, whereas global QoL did not. Decreases in patient satisfaction after treatment were found for general satisfaction with care, interpersonal skills of doctors, and satisfaction with the exchange of information within the care team. Somewhat unexpectedly, satisfaction scores decreased more among patients treated with curative intent than among those treated with palliative intent. Our results have important implications for clinical practice and are relevant for those wishing to maintain and even improve patient satisfaction after treatment in their practice.
A

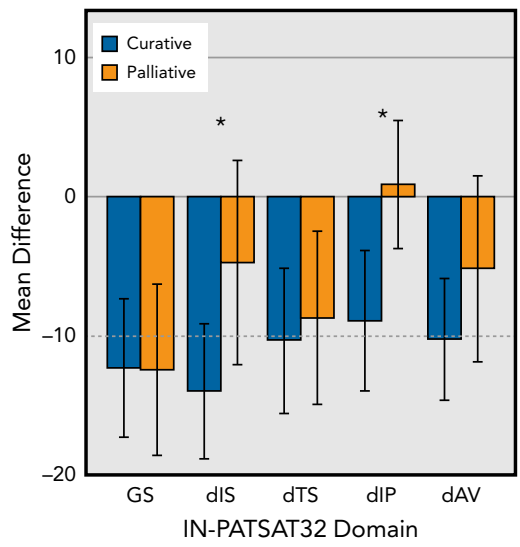

B

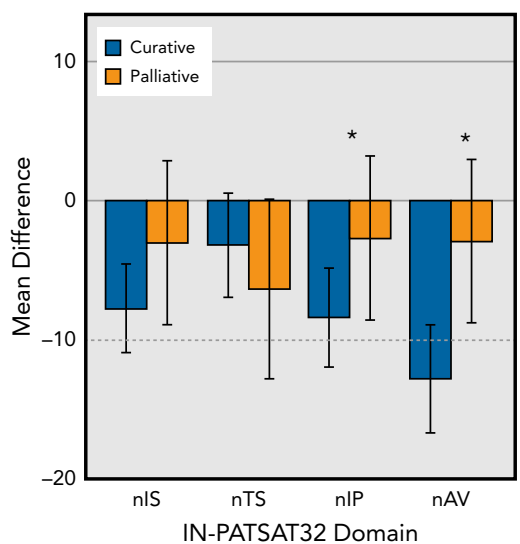

C

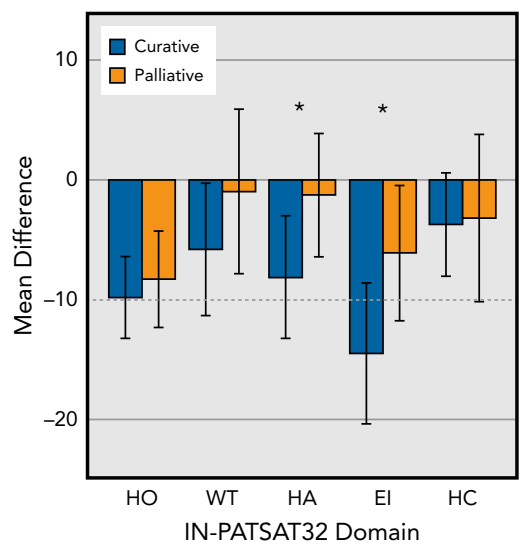

Figure 2. Mean difference in (A) general satisfaction with care and satisfaction with doctors, (B) satisfaction with nurses, and (C) satisfaction with other domains before and after treatment of pancreatic or periampullary cancer.

Abbreviations: HA, hospital access; HC, hospital comfort; dAV, doctor availability; dIP, doctor information provision; dIS, doctor interpersonal skills; dTS, doctor technical skills; El, exchange of information; GS, general satisfaction with care; HO, other hospital staff; IN-PATSAT32, EORTC cancer in-patient satisfaction with care questionnaire; nAV, nurse availability; nIP, nurse information provision; nIS, nurse interpersonal skills; nTS, nurse technical skills; WT, waiting time.

${ }^{\star} P<.05$ (all tests were based on unpaired $t$ test). 


\begin{tabular}{|c|c|c|c|c|c|c|}
\hline Characteristic & $\beta$ Value & $95 \% \mathrm{Cl}$ & $P$ Value & $\beta$ Value & $95 \% \mathrm{Cl}$ & $P$ Value \\
\hline Female sex & 5.1 & -1.4 to 11.6 & .12 & 1.5 & -3.3 to 6.3 & .54 \\
\hline Age $\geq 65$ y & 1.9 & -4.6 to 8.4 & .57 & & & \\
\hline ECOG performance status $<2$ & 1.1 & -7.3 to 9.6 & .79 & & & \\
\hline Treatment with curative intent & -4.9 & -11.4 to 1.6 & .13 & -2.1 & -6.9 to 2.5 & .36 \\
\hline \multicolumn{7}{|l|}{ Treatment center } \\
\hline A & Ref & & & & & \\
\hline B & -1.0 & -8.0 to 5.9 & .77 & & & \\
\hline Emotional functioning & 0.2 & -0.01 to 0.3 & .05 & 0.1 & -0.1 to 0.3 & .31 \\
\hline Cognitive functioning & 0.2 & 0.02 to 0.3 & .03 & 0.2 & -0.1 to 0.4 & .24 \\
\hline Social functioning & 0.1 & -0.01 to 0.3 & .08 & -0.01 & -0.2 to 0.2 & .89 \\
\hline
\end{tabular}

It was surprising to find decreased satisfaction scores after treatment, because patients may be expected to appreciate treatment of their disease. This expectation has not yet been tested, however, or previous studies did not show a clear relationship. Previous studies have only used cross-sectional assessments of patient satisfaction after treatment of cancer or are heterogeneous in terms of the methods and questionnaires used, impeding cross-study comparisons. ${ }^{24-27}$

Because the interpersonal skills of doctors and exchange of information within the care team were found to be particularly important determinants of satisfaction with care, our results indicate that communication skills may be important targets for improvement to increase patient satisfaction. This has also been suggested previously. ${ }^{28-30}$ It is difficult to determine whether communication was truly insufficient in the 3 dedicated pancreatic cancer centers or if this was predominantly the patients' perception. Furthermore, because of the design of the IN-PATSAT32, it is not possible to determine in hindsight which doctor or doctors (eg, the physician present during pretreatment or posttreatment outpatient visit or the resident during admission) were meant by patients.

Our results may indicate 2 directions for future improvements. First, communication and interpersonal skills need to be improved, specifically with regard to diagnosis and treatment planning, but especially during and after treatment. Second, patient expectations at the outset need to be managed better.
Various studies investigating patient satisfaction have suggested that improved information provision is important. ${ }^{31-36}$ In fact, information provision is a prerequisite of shared decision-making, which, in turn, has been related to satisfaction with care. ${ }^{8,28,37}$ Additionally, if patients are well-informed about the risks of treatment (eg, complications, recurrence), coping with complications may be improved..$^{38}$ This is particularly important because complications after surgery have been shown to decrease satisfaction with care, although such complications are inherent to surgical therapy. Decreases in satisfaction with care may thus be more pronounced in surgically treated patients. ${ }^{39}$ This may explain why larger decreases in satisfaction with care were observed among patients treated with curative intent (ie, surgical resection) than among those treated with palliative intent (ie, systemic therapy). However, in a study investigating satisfaction among patients treated with curative and palliative intent for upper gastrointestinal cancer, patient satisfaction was independent of (major) treatment-related complications. ${ }^{25}$ Therefore, a difference in follow-up schemes and practice of surgeons versus medical oncologists may contribute to our findings. The patientsurgeon relationship consists of intense contact in the period immediately after surgery, followed by less contact during follow-up, whereas the patient-medical doctor relationship consists of intense contact during (longterm) follow-up after the postoperative period. Therefore, the effect of specific communication strategies in 
the pretreatment and posttreatment phases on patient satisfaction should be investigated further in future studies, especially in the curative- and palliative-intent groups separately.

Communication (or rather, a lack thereof) in the posttreatment phase may also contribute to (lower) patient satisfaction. In the Netherlands, as in many countries, multidisciplinary team meetings are mandatory for the treatment of patients with pancreatic cancer.$^{40}$ Much of the effort of these multidisciplinary team meetings is directed at a rapid diagnostic phase and early treatment initiation. ${ }^{41}$ Patients spend 1 or 2 days undergoing various diagnostic tests and receive much information, a diagnosis, and a tailored treatment plan. Specialized case managers and oncology nurses guide patients during this time and provide additional information and psychosocial support. ${ }^{42,43}$ This psychosocial care is important to patients with cancer. ${ }^{44}$ After treatment, contact with the hospital staff is often reduced, and psychosocial support may rely predominantly on family and friends. In our study, the first questionnaire was sent to patients directly after the (fast-track) outpatient clinic and before treatment. During this time, patients received intensive guidance and psychosocial support. However, after treatment, when patients had to rely mostly on their own psychosocial support system and much less on hospital staff, satisfaction with care was lower. This is especially true in the curative setting, because patients treated with palliative intent may still visit the hospital more frequently than those treated with curative intent (eg, outpatient visits for administration of systemic therapy and potentially for treatment of chemotherapy-related toxicity). In our study, 10 of 15 patients with pancreatic cancer treated with curative intent received adjuvant chemotherapy. However, satisfaction scores among these patients were not significantly higher than among the 30 patients treated with curative intent who did not receive adjuvant chemotherapy (data not shown). Although much effort is already directed at attention to psychosocial problems during follow-up after treatment with curative intent, this may be further optimized by, for example, the use of specific signaling instruments. ${ }^{45}$

We did not identify associations between QoL and patient satisfaction, a finding that also has been found in previous studies. ${ }^{25,45}$ Other factors associated with patient satisfaction remain to be identified. Overall, there were no large changes in QoL 3 months after initiation of treatment, a finding that has been described previously. ${ }^{46,47}$

Our study must be interpreted within the context of its design. The IN-PATSAT32 module was designed to measure inpatient satisfaction with care, whereas some of the patients in our study received outpatient treatment (ie, systemic therapy). The EORTC QoL group recently introduced an extended module with a provisional list of 57 additional items to be added to the original module and applicable to any cancer care setting. ${ }^{1}$ However, because of the high treatment intensity in patients with pancreatic cancer, we believe that use of the current module was justified. All single-scale and multiscale domains seem applicable in pancreatic cancer. ${ }^{21}$ For example, waiting times for palliative systemic therapy are also applicable in the outpatient setting (ie, waiting times to get an outpatient appointment). Second, we had no information on postoperative complications or data on toxicity. This was caused by referral patterns in the Netherlands, where patients are often treated for adverse events (eg, toxicity) in a local hospital. In the future, patient-reported outcome data will be combined with clinical data obtained from audits and other registries. ${ }^{19}$ However, treatment outcomes (eg, complications) in terms of QoL were not related to patient satisfaction. Because of the design of the study, we had no information on patients who were eligible but not included in this study. Although we aimed to include all consecutive patients, not all patients participated, which may limit generalizability. Declining response rates over time are common in health-related QoL studies, particularly those involving patients with advanced disease. In the present study, the response rate after 3 months was $78 \%$, which is remarkably high compared with other studies, given that many patients were treated with palliative intent. ${ }^{46}$ Selective attrition, however, in which only the fittest patients complete the follow-up questionnaires, cannot be ruled out. Finally, the relatively small number of patients introduces statistical uncertainty.

\section{Conclusions}

Satisfaction with care decreased after treatment of pancreatic and periampullary cancer in this prospective cohort, whereas QoL did not. Expectation management through shared decision-making and attention to psychosocial problems and healthcare professionals' communication skills may improve patients' satisfaction with care.

Submitted October 10, 2019; accepted for publication January 2, 2020.

Author contributions: Study concept and design: Mackay, van Rijssen Andriessen, Besselink, Van Laarhoven. Data acquisition and analysis: Mackay, van Rijssen, Andriessen, Besselink, Van Laarhoven. Data interpretation: All authors. Manuscript preparation: All authors. Critical revision: All authors.

Disclosures: The authors have disclosed that they have not received any financial consideration from any person or organization to support the preparation, analysis, results, or discussion of this article.

Funding: This study was partially supported by a grant from the Dutch Cancer Society (grant UVA2013-5842; H.W.V.L.).

Correspondence: Hanneke W. van Laarhoven, MD, PhD, Department of Medical Oncology, D3-312, Cancer Center Amsterdam, Amsterdam UMC, University of Amsterdam, Meibergdreef 9, 1105 AZ Amsterdam, the Netherlands. Email: h.vanlaarhoven@amsterdamumc.nl 


\section{References}

1. Brédart A, Beaudeau A, Young $T$, et al. The European Organization for Research and Treatment of Cancer - satisfaction with cancer care questionnaire: revision and extended application development. Psychooncology 2017;26:400-404.

2. Kleefstra SM, Zandbelt LC, de Haes HJ, et al. Trends in patient satisfaction in Dutch university medical centers: room for improvement for all. BMC Health Serv Res 2015;15:112.

3. Barr JK, Giannotti TE, Sofaer S, et al. Using public reports of patient satisfaction for hospital quality improvement. Health Serv Res 2006;41:663-682.

4. Riiskjær E, Ammentorp J, Nielsen JF, et al. Patient surveys-a key to organizational change? Patient Educ Couns 2010;78:394-401.

5. Aiken LH, Sermeus W, Van den Heede K, et al. Patient safety, satisfaction, and quality of hospital care: cross sectional surveys of nurses and patients in 12 countries in Europe and the United States. BMJ 2012;344:e1717.

6. Liu Y, Malin JL, Diamant AL, et al. Adherence to adjuvant hormone therapy in low-income women with breast cancer: the role of provider-patient communication. Breast Cancer Res Treat 2013;137:829-836.

7. Gupta D, Rodeghier M, Lis CG. Patient satisfaction with service quality in an oncology setting: implications for prognosis in non-small cell lung cancer. Int J Qual Health Care 2013;25:696-703.

8. Kleeberg UR, Feyer P, Günther W, et al. Patient satisfaction in outpatient cancer care: a prospective survey using the PASQOC questionnaire. Support Care Cancer 2008;16:947-954.

9. Williams B, Coyle J, Healy D. The meaning of patient satisfaction: an explanation of high reported levels. Soc Sci Med 1998;47:1351-1359.

10. Conroy $T$, Desseigne $F$, Ychou M, et al. FOLFIRINOX versus gemcitabine for metastatic pancreatic cancer. N Engl J Med 2011;364:1817-1825.

11. Cameron JL, He J. Two thousand consecutive pancreaticoduodenectomies. J Am Coll Surg 2015;220:530-536.

12. Carrato A, Falcone A, Ducreux M, et al. A systematic review of the burden of pancreatic cancer in Europe: real-world impact on survival, quality of life and costs. J Gastrointest Cancer 2015;46:201-211.

13. Suker M, Beumer BR, Sadot E, et al. FOLFIRINOX for locally advanced pancreatic cancer: a systematic review and patient-level meta-analysis. Lancet Oncol 2016;17:801-810.

14. Von Hoff DD, Ervin T, Arena FP, et al. Increased survival in pancreatic cancer with nab-paclitaxel plus gemcitabine. N Engl J Med 2013;369:1691-1703.

15. McPhee JT, Hill JS, Whalen GF, et al. Perioperative mortality for pancreatectomy: a national perspective. Ann Surg 2007;246:246-253.

16. Kotronoulas G, Kearney N, Maguire R, et al. What is the value of the routine use of patient-reported outcome measures toward improvement of patient outcomes, processes of care, and health service outcomes in cancer care? A systematic review of controlled trials. J Clin Oncol 2014;32: 1480-1501.

17. Lis CG, Rodeghier M, Grutsch JF, et al. Distribution and determinants of patient satisfaction in oncology with a focus on health related quality of life. BMC Health Serv Res 2009;9:190.

18. Bleich SN, Ozaltin E, Murray CK. How does satisfaction with the healthcare system relate to patient experience? Bull World Health Organ 2009; 87:271-278.

19. Coebergh van den Braak RRJ, van Rijssen LB, van Kleef JJ, et al Nationwide comprehensive gastro-intestinal cancer cohorts: the 3P initiative. Acta Oncol 2018;57:195-202.

20. van de Poll-Franse LV, Horevoorts N, van Eenbergen M, et al. The Patient Reported Outcomes Following Initial treatment and Long term Evaluation of Survivorship registry: scope, rationale and design of an infrastructure for the study of physical and psychosocial outcomes in cancer survivorship cohorts. Eur J Cancer 2011:47:2188-2194.

21. Brédart A, Bottomley A, Blazeby JM, et al. An international prospective study of the EORTC cancer in-patient satisfaction with care measure (EORTC IN-PATSAT32). Eur J Cancer 2005;41:2120-2131.

22. Aaronson NK, Ahmedzai S, Bergman B, et al. The European Organization for Research and Treatment of Cancer QLQ-C30: a quality-of-life instrument for use in international clinical trials in oncology. J Natl Cancer Inst 1993;85:365-376

23. Osoba D, Rodrigues G, Myles J, et al. Interpreting the significance of changes in health-related quality-of-life scores. J Clin Oncol 1998;16:139-144.
24. Lis CG, Rodeghier M, Gupta D. Distribution and determinants of patient satisfaction in oncology: a review of the literature. Patient Prefer Adherence 2009;3:287-304.

25. Avery KN, Metcalfe C, Nicklin J, et al. Satisfaction with care: an independent outcome measure in surgical oncology. Ann Surg Oncol 2006;13:817-822.

26. Batbaatar E, Dorjdagva J, Luvsannyam A, et al. Determinants of patient satisfaction: a systematic review. Perspect Public Health 2017;137:89-101.

27. Gupta D, Markman M, Rodeghier M, et al. The relationship between patient satisfaction with service quality and survival in pancreatic cancer Patient Prefer Adherence 2012;6:765-772.

28. Kleeberg UR, Tews JT, Ruprecht $T$, et al. Patient satisfaction and quality of life in cancer outpatients: results of the PASQOC study. Support Care Cancer 2005;13:303-310.

29. Ong LM, Visser MR, Lammes FB, et al. Doctor-patient communication and cancer patients' quality of life and satisfaction. Patient Educ Couns 2000;41:145-156.

30. Vashisht A, Domoney CL, Handscomb K, et al. Patient satisfaction with the care provided at a gynaecology oncology clinic. J Obstet Gynaecol 2000; 20:183-184

31. Thomas S, Glynne-Jones R, Chait I. Is it worth the wait? A survey of patients' satisfaction with an oncology outpatient clinic. Eur J Cancer Care (Engl) 1997;6:50-58.

32. Bergenmar $M$, Nylén $U$, Lidbrink $E$, et al. Improvements in patient satisfaction at an outpatient clinic for patients with breast cancer. Acta Oncol 2006:45:550-558.

33. Brédart A, Razavi D, Robertson C, et al. Assessment of quality of care in an oncology institute using information on patients' satisfaction. Oncology 2001:61:120-128.

34. McNamara S, Brown J. An audit of patient satisfaction with a neurooncology clinic. Eur J Oncol Nurs 2003;7:200-203.

35. Wiggers $\mathrm{JH}$, Donovan $\mathrm{KO}$, Redman $\mathrm{S}$, et al. Cancer patient satisfaction with care. Cancer 1990;66:610-616.

36. Brown RF, Hill C, Burant CJ, et al. Satisfaction of early breast cancer patients with discussions during initial oncology consultations with a medical oncologist. Psychooncology 2009;18:42-49.

37. Eide H, Graugaard $\mathrm{P}$, Holgersen $\mathrm{K}$, et al. Physician communication in different phases of a consultation at an oncology outpatient clinic related to patient satisfaction. Patient Educ Couns 2003;51:259-266.

38. Coulter A, Entwistle V, Gilbert D. Sharing decisions with patients: is the information good enough? BMJ 1999;318:318-322.

39. Di Cristofaro L, Ruffolo C, Pinto E, et al. Complications after surgery for colorectal cancer affect quality of life and surgeon-patient relationship. Colorectal Dis 2014;16:0407-419.

40. van Rijssen LB, van der Geest LG, Bollen TL, et al. National compliance to an evidence-based multidisciplinary guideline on pancreatic and periampullary carcinoma. Pancreatology 2016;16:133-137.

41. Basta $Y L, B a u r O L$, van Dieren S, et al. Is there a benefit of multidisciplinary cancer team meetings for patients with gastrointestinal malignancies? Ann Surg Oncol 2016;23:2430-2437.

42. Burnet $K$, Chapman D, Wishart $G$, et al. Nurse specialists in breast care: a developing role. Nurs Stand 2004;18:38-42.

43. Haward R, Amir Z, Borrill C, et al. Breast cancer teams: the impact of constitution, new cancer workload, and methods of operation on their effectiveness. Br J Cancer 2003;89:15-22.

44. Walker MS, Ristvedt SL, Haughey BH. Patient care in multidisciplinary cancer clinics: does attention to psychosocial needs predict patient satisfaction? Psychooncology 2003;12:291-300.

45. Pompili C, Tiberi M, Salati M, et al. Patient satisfaction with health-care professionals and structure is not affected by longer hospital stay and complications after lung resection: a case-matched analysis. Interact Cardiovasc Thorac Surg 2015;20:236-241

46. Heerkens HD, Tseng DS, Lips IM, et al. Health-related quality of life after pancreatic resection for malignancy. Br J Surg 2016;103:257-266.

47. Gourgou-Bourgade S, Bascoul-Mollevi C, Desseigne F, et al. Impact of FOLFIRINOX compared with gemcitabine on quality of life in patients with metastatic pancreatic cancer: results from the PRODIGE 4/ACCORD 11 randomized trial. J Clin Oncol 2013;31:23-29. 
Supplemental online content for:

\section{Patient Satisfaction and Quality of Life Before and After Treatment of Pancreatic and Periampullary Cancer: A Prospective Multicenter Study}

Tara M. Mackay, MD; Lennart B. van Rijssen, MD; Jurr O. Andriessen, BSc; Mustafa Suker, MD; Geert-Jan Creemers, MD, PhD; Ferry A. Eskens, MD, PhD; Ignace H. de Hingh, MD, PhD; Lonneke V. van de Poll-Franse, PhD; Mirjam A.G. Sprangers, PhD; Olivier R. Busch, MD, PhD; Johanna W. Wilmink, MD, PhD; Casper H. van Eijck, MD, PhD; Marc G. Besselink, MD, PhD; and Hanneke W. van Laarhoven, MD, PhD; on behalf of the Dutch Pancreatic Cancer Group

J Natl Compr Canc Netw 2020;18(6):704-711

eTable 1: Sensitivity Analysis of IN-PATSAT32 Scores Before and After Treatment eTable 2: Sensitivity Analysis of EORTC QLQ-C30 Scores Before and After Treatment 


\section{eTable 1. Sensitivity Analysis of IN-PATSAT32 Scores Before and After Treatment}

\begin{tabular}{|c|c|c|c|c|c|c|}
\hline & \multicolumn{2}{|c|}{ Before Treatment } & \multicolumn{2}{|c|}{ After Treatment } & \multirow[b]{2}{*}{$P$ Value } & \multirow{2}{*}{$\begin{array}{c}\text { Clinically } \\
\text { Meaningful }\end{array}$} \\
\hline & Mean & SD & Mean & SD & & \\
\hline General satisfaction with care & 74.2 & 10.5 & 61.0 & 13.3 & $<.001$ & Yes \\
\hline Doctor interpersonal skills & 74.7 & 13.6 & 62.8 & 15.1 & $<.001$ & Yes \\
\hline Doctor technical skills & 77.1 & 11.6 & 65.4 & 15.6 & $<.001$ & - \\
\hline Doctor information provision & 74.1 & 13.1 & 68.0 & 15.0 & .01 & - \\
\hline Doctor availability & 69.3 & 14.4 & 60.2 & 15.2 & $<.001$ & - \\
\hline Nurse interpersonal skills & 72.9 & 11.3 & 65.9 & 13.3 & $<.001$ & - \\
\hline Nurse technical skills & 73.3 & 11.2 & 67.6 & 12.7 & .01 & - \\
\hline Nurse information provision & 69.1 & 9.6 & 61.6 & 11.8 & $<.001$ & - \\
\hline Nurse availability & 66.7 & 10.2 & 58.1 & 13.1 & $<.001$ & - \\
\hline Other hospital staff & 68.8 & 10.5 & 58.5 & 8.1 & $<.001$ & - \\
\hline Waiting time & 62.4 & 13.4 & 56.4 & 13.3 & .02 & - \\
\hline Hospital access & 61.4 & 13.0 & 56.0 & 13.6 & .02 & - \\
\hline Exchange of information & 64.0 & 14.4 & 51.5 & 11.0 & $<.001$ & Yes \\
\hline Hospital comfort & 62.8 & 13.4 & 59.0 & 12.7 & .12 & - \\
\hline
\end{tabular}

Abbreviation: IN-PATSAT32, EORTC cancer in-patient satisfaction with care questionnaire.

\section{eTable 2. Sensitivity Analysis of QLQ-C30 Scores Before and After Treatment}

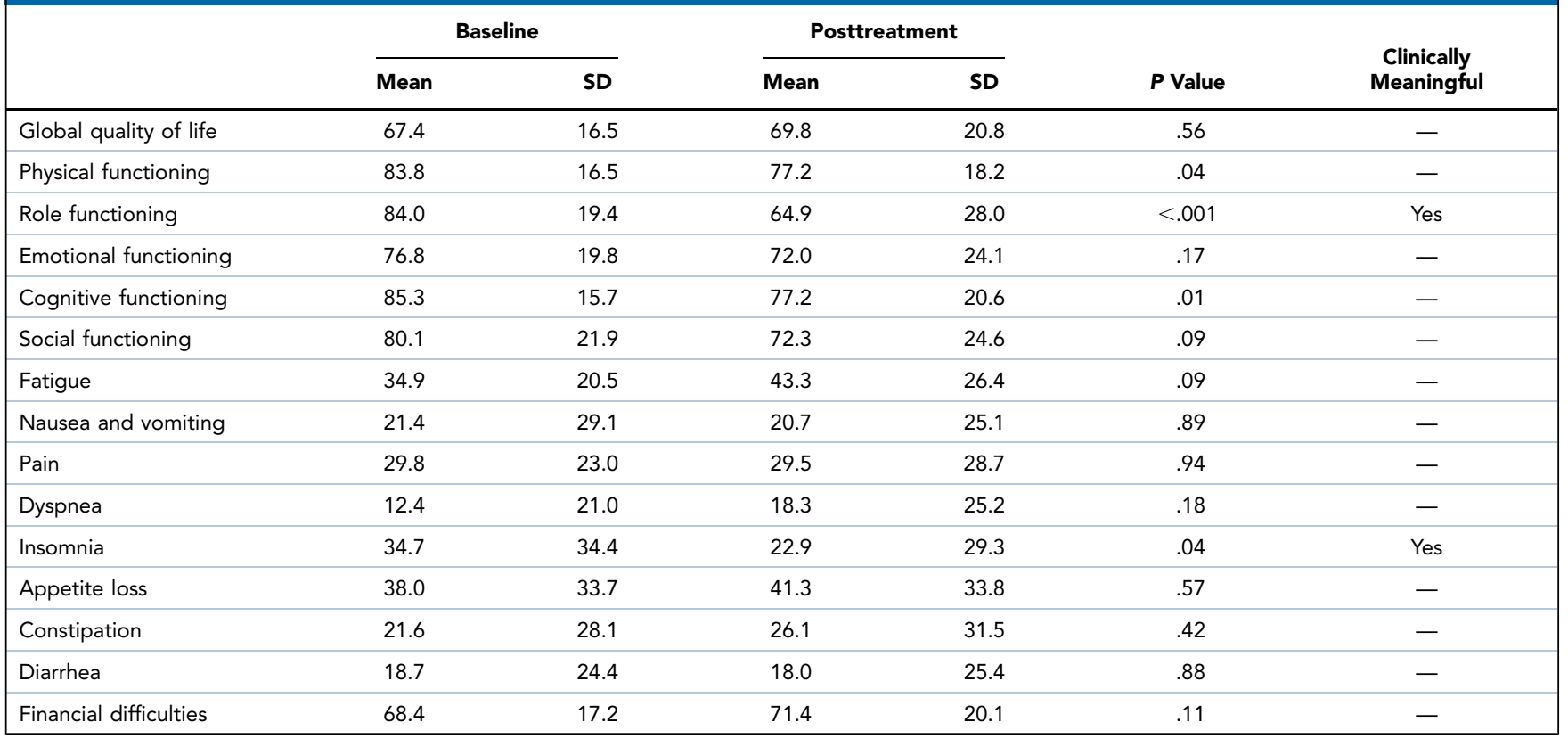

Abbreviation: QLQ-C30, EORTC Core Quality of Life Questionnaire. 